\title{
Molecular Occurrence and Therapeutic Management of Canine Parvovirus Infection in Dogs
}

\author{
D. Kataria*, D. Agnihotri, V. K. Jain, G. Charaya and Y. Singh \\ Department of Veterinary Medicine, College of Veterinary Sciences, Lala Lajpat Rai \\ University of Veterinary and Animal Sciences, Hisar, Haryana-125004, India \\ *Corresponding author
}

Keywords

Canine parvovirus, gastroenteritis, PCR

Article Info

Accepted:

08 January 2020

Available Online:

10 February 2020

\section{A B S T R A C T}

CPV infection is considered as the most pathogenic and contagious infection of dogs causing haemorrhagic gastroenteritis. Molecular detection using PCR is used widely for detection and confirmation of CPV infection in dogs. Present study was conducted to detect CPV in the faeces of dogs showing clinical signs of hemorrhagic gastroenteritis. A total of $52 \mathrm{dogs}$ suffering from gastroenteritis were screened for the study, out of which 31 dogs were found to be affected with CPV infection. The occurrence of CPV infection was more in male (58.06 than female $(41.94 \%)$ dogs. Labrador and non-descriptive breed dogs were found to have 22.59 percent occurrence each followed by GSD (19.36\%) and Rottweiler (12.90\%). Dogs with uneven history of vaccination were found to be affected more $(64.52 \%)$ than dogs with history of proper vaccination. Maximum no. of dogs affected were from age group less than one year $(93.55 \%)$ out of which most of the dogs were of less than 6 months age (67.74\%). Suffering dogs were divided into random groups and administered with antibiotics, antioxidants and supportive therapy.

\section{Introduction}

Gastroenteritis is characterized by clinical signs such as diarrhoea, vomiting with or without blood, inappetance, lethargy, fever, anaemia and dehydration. Viruses are detected in 40-60 percent of diarrhoeic faecal samples (Decaro et al., 2007) thus; viral gastroenteritis is a major clinical problem in dogs. CPV infection is considered as the most pathogenic and highly contagious viral infection of dogs causing haemorrhagic gastroenteritis and myocarditis mainly in pups less than six months of age. Acute CPV-2 enteritis can be seen in dogs of any breed, age or sex, but puppies between 6 weeks and 6 months of age are more susceptible (Panda et al., 2009). 
Canine parvovirus is a single stranded, negative-sense DNA, $5.2 \mathrm{~kb}$ in length and has three structural (VP1, VP2 and VP3) and two non-structural (NS1 and NS2) proteins. Molecular diagnostic techniques like PCR had been the most reliable techniques having high degree of sensitivity and specificity in detecting CPV in faecal samples (Srinivas et al., 2013 and Agnihotri et al., 2017). The present study was conducted to find out the occurrence of CPV infection in dogs and to evaluate the efficacy of two different antibiotics in different combinations with antioxidants such as vitamin $\mathrm{C}$ and $\mathrm{N}$ acetylcysteine along with supportive therapy.

\section{Materials and Methods}

Fifty two faecal samples were collected using sterile swabs from diarrhoeic dogs reported to Veterinary Clinical Complex, LUVAS, Hisar with clinical signs of vomiting, diarrhoea or haemorrhagic diarrhoea, hemato-emesis, lethargy, dehydration and depression. The samples were collected in sterile PBS $(\mathrm{pH}$ 7.4), vortexed and preserved at $-20^{\circ} \mathrm{C}$ till further processing. The samples were processed for the extraction of viral DNA using QIAamp DNA Mini Kit and were screened for the presence of CPV DNA by conventional PCR using published primers (Table 1) targeting CPV-2ab (Kumar et al., 2011).

Commercially available live attenuated multivalent vaccine for CPV (Nobivac
DHPPiL, MSD Pvt. Ltd) served as positive control for the PCR assay. Approximately $5 \mathrm{ml}$ blood was collected from cephalic/ saphanous vein aseptically. Two $\mathrm{ml}$ of blood in EDTA was used for hematological examination using automated hematology cell counter (MS4s, Melet Schlosing Lab.) and 3 $\mathrm{ml}$ blood was utilized for obtaining serum which was stored at $-20^{\circ} \mathrm{C}$ till further analysis. The serum samples were analyzed for estimation of biochemical parameters using automatic analyzer (EM Destiny 180, Erba Diagnostics Mannheim $\mathrm{GmbH}$ ). Electrolytes including sodium $(\mathrm{mEq} / \mathrm{L})$, potassium $(\mathrm{mEq} / \mathrm{L})$ and chloride $(\mathrm{mEq} / \mathrm{L})$ were measured in EasyLyte EXPAND analyzer.

PCR was performed in Thermal cycler in 12.5 $\mu \mathrm{l}$ reaction containing $3 \mu \mathrm{l}$ of template DNA, $6.25 \mu \mathrm{l}$ of PCR master mix (2X concentration) (Thermo-scientific) [containing $15 \mathrm{mM}$ $\mathrm{MgCl} 2,1 \mu 1$ of dNTP's mix (10mM), $1 \mu 1$ of Taq DNA polymerase $(1 \mathrm{U} / \mu 1)], 0.5 \mu 1$ each of forward and reverse primer (10 pmoles concentration) and $2.25 \mu \mathrm{l}$ of nuclease free water. Cyclic conditions for pCPV-2ab primers included one cycle of initial denaturation at $94^{\circ} \mathrm{C}$ for $5 \mathrm{~min}$., followed by 35 cycles of denaturation at $94^{\circ} \mathrm{C}$ for 30 sec., annealing at $55^{\circ} \mathrm{C}$ for $1 \mathrm{~min}$. and extension at $72^{\circ} \mathrm{C}$ for $1 \mathrm{~min}$. and final extension at $72^{\circ} \mathrm{C}$ for $15 \mathrm{~min}$. The PCR products were analyzed in $1.5 \%$ agarose gel electrophoresis and visualized under UV transilluminator Gel$\operatorname{Doc}^{\mathrm{TM}}$ (BIO-RAD).

Table.1 Details of Primer pair used for the amplification of CPV viral DNA

\begin{tabular}{|c|c|c|c|c|}
\hline S. No. & Primer & Sequence & $\begin{array}{c}\text { Amplico } \\
\text { n }\end{array}$ & Reference \\
\hline 1. & pCPV-2ab $($ F $)$ & GAAGAGTGGTTGTAAATAATT & 681 bp & $\begin{array}{c}\text { Kumar } \text { et al., } \\
2011\end{array}$ \\
\hline 2. & $\begin{array}{c}\text { pCPV-2ab } \\
(\mathbf{R})\end{array}$ & CCTATATAACCAAAGTTAGTAC & 681 bp & $\begin{array}{c}\text { Kumar } \text { et al. } \text {, } \\
2011\end{array}$ \\
\hline
\end{tabular}




\section{Results and Discussion}

Total number of dogs registered from March' 2018 to February' 2019 in Veterinary Clinical Complex, LUVAS, Hisar were 4847 out of which 593 dogs were found to be suffering from gastroenteritis (12.24\%). Although occurrence of gastroenteritis was seen throughout the year but maximum number of gastroenteritic cases were observed in winter months (30.19\%) followed by summer $(25.46 \%)$, spring (24.28\%) and autumn (20.07\%) months.

The reason of this might be the stress due of adverse climate on immunosuppressed dogs. Fifty two diarrhoeic dogs were screened for the presence of CPV infection out of which thirty one samples (59.62\%) were found positive for CPV (Figure 1). However out of thirty six dogs in six different groups, twenty one dogs found positive for CPV.

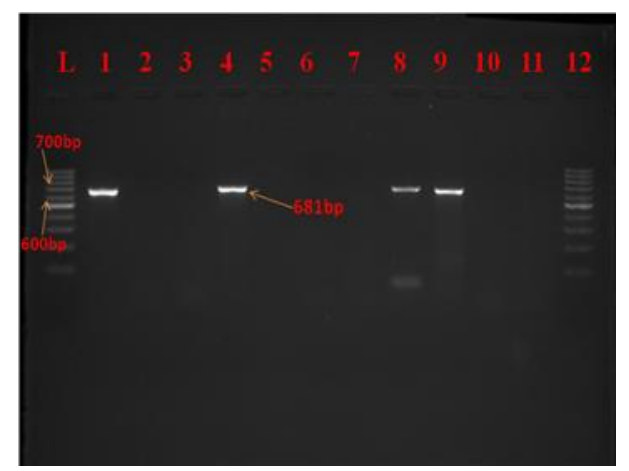

Figure.1 AGE of $681 \mathrm{bp}$ size PCR product of CPV positive samples

In a similar study by Agnihotri et al., (2017), comparatively lower per cent prevalence was reported where a total of 50 samples were screened and $25(50 \%)$ were found positive for CPV by designed PCR while 18 (36\%) were found positive when published primers were used. On the contrary a comparatively higher percent prevalence of CPV in dogs was reported in the study by Bishnoi et al., (2016) who found $26(65 \%)$ out of 40 suspected faecal samples to be positive for CPV using nested PCR targeting the $\mathrm{N}$ gene which was more as compared to positive cases by simplex PCR which accounted for $22(55 \%)$ samples. In another study of Punjab region, a total of hundred rectal samples from dogs suspected of CPV were screened using PCR, nested PCR, individual real time PCR probe assay and multiplex real time PCR probe assay and the assays detected 11 (11\%), 50 (50\%), 44 (44\%) and 26 (26\%) cases positive for CPV respectively (Kaur et al., 2016).

Hao et al., (2019) reported that CPV was the most common virus, appearing in 70 per cent (14/20) of anal swabs using multiplex PCR assay. In the present study maximum occurrence of CPV gastroenteritis was reported in mixed breed (22.58\%) and Labrador (22.58\%) breed of dogs followed by German Shepherd (19.35\%), Rottweiler (12.90\%) and Pitbull (6.45\%). Dogs of Gaddi, French Mastiff, Spitz, Pug and Bully breed were observed to have 3.22 per cent occurrence of CPV infection. Similar findings were reported by Agnihotri et al., (2017) and Bishnoi et al., (2016).

This could be due to more reporting of these breeds or because of the more preference of owners for these breeds in this particular area of study. The maximum occurrence of canine parvoviral gastroenteritis was observed in dogs of six months or less age (41.93\%), followed by dogs of three months or less in age $(25.81 \%)$. Dogs of more than six months and less than one year of age were having 25.81 per cent occurrence while dogs above one year of age were observed to have 6.45 percent prevalence of viral gastroenteritis.

The results of the present study are in accordance with the earlier reports (Agnihotri et al., 2017 and Akgul et al., 2019). Younger dogs are generally protected from CPV-2 infection by maternally-derived immunity. 
Increased intestinal epithelial turn over caused by the changes in microflora, diet (weaning) and diminishing maternal antibody level are the predisposing factors to CPV infection in pups (Decaro et al., 2004). In the present study, 58.06 per cent occurrence of CPV was found in the male dogs as compared to the female dogs $(41.94 \%)$.

Higher incidence of canine parvo virus in gastroenteritic male dogs was also reported by Agnihotri et al., (2017); Bishnoi et al., (2016) and Surendhar et al., (2018). Higher incidence in males might be because of preference of pet owners for keeping the male dogs. It was observed in the present study that twenty dogs out of thirty one dogs $(64.52 \%)$ found positive for canine parvo viral gastroenteritis did not have any history of vaccination. Similar trend was also observed in the deworming status of CPV positive dogs where twenty one out of thirty one dogs $(67.74 \%)$ suffering from canine parvo viral gastroenteritis did not have any history of deworming.

Similar findings were reported by Bishnoi et al., 2016; Agnihotri et al., (2017) and Akgul et al., 2019 in their study where higher prevalence $(76.92 \%, 96.66 \%$ and $83.63 \%$ respectively) of CPV infection was observed in unvaccinated dogs as compared to the vaccinated dogs. Cavalli et al., (2008) suggested that susceptibility to CPV-2 infection often coincides with the time when puppies are separated from dams as the level of protective immunity or maternal immunity declined.

\section{Clinical findings}

Commonly observed clinical signs in parvo virus affected dogs were dehydration (93.55\%), lethargy (90.32\%), inappetence to anorexia $(90.32 \%)$ and pallor mucous membrane $(83.87 \%)$. Other clinical signs observed were vomiting without blood (74.19\%), diarrhoea without blood $(38.71 \%)$, and haemorrhagic diarrhoea (35.48\%) (Figure 2 and 3) followed by fever (12.90\%) and haematoemesis $(6.45 \%)$. Similar findings were reported by Agnihotri et al., (2017) and Bishnoi et al., (2016) in their studies. On the contrary Akgul et al., (2019) observed that vomiting was detected at a higher rate $(100 \%)$ followed by haemorrhagic diarrhea $(67.27 \%)$. They observed non haemorrhagic diarrhoea in 27.27 per cent dogs affected with CPV infection.

\section{Therapeutic trial}

The affected dogs were randomly divided into six groups (G2, G3, G4, G5, G6, and G7) at the start of treatment each group having six dogs irrespective of their parvo virus status. Blood and serum samples were collected on day 1, 3 and 5 of treatment for hematological and biochemical studies. Group G1 consisted of the healthy group of dogs which came for routine vaccination.

Dogs in group 2 were administered with ceftriaxone-tazobactum @25mg/kg b.wt. i.m. once daily and Vitamin C @20mg/kg b.wt. i.v. for five days while in group 3 only antibiotic ceftriaxone at same dose rate and interval was administered but without any antioxidant. Affected dogs in Group 4 were administered with Ampicillin-cloxacillin (@ $10 \mathrm{mg} / \mathrm{kg}$ b.wt. i.m. twice daily for five days Metronidazole (@15mg/kg b.wt. i.v. thrice daily for five days and NAC @ 70mg/Kg b.wt. i.v. once daily for five days) and group 5 dogs were administered with the same antibiotics as given for group 4 but without NAC.

Dogs in group 6 were administered with both the antioxidants i.e. Vitamin $\mathrm{C}$ and NAC along with Ceftriaxone while those in group 7 were administered ampicillin-cloxacillin and 
metronidazole along with both antioxidants at the dose rate and schedule as mentioned for the other groups. The supportive and symptomatic treatment in different groups included the administration of intravenous fluid Ringer's Lactate (RL), Normal Saline Solution (NSS) or Dextrose Normal Saline (DNS) on the basis of dehydration status and the clinical condition, antacids (pantaprazole @ $1 \mathrm{mg} / \mathrm{kg}$ i.v.), antiemetic (prochlorperazine $@ 0.2 \mathrm{mg} / \mathrm{kg} \quad$ b.wt. i.m.), antihistaminic (pheniramine maleate @ $0.5 \mathrm{mg} / \mathrm{kg}$ b.wt. i.m.), antipyretic (analgin @25mg/kg b.wt. i.m.), vitamin B complex, amino acid preparation, antifibrinolytic agents (Tranexamic acid @ $10 \mathrm{mg} / \mathrm{kg}$ b.wt.) were administered as per the clinical condition of the animal.

Clinical recovery of the affected dogs was determined on the basis of remission of clinical signs on day 5 of treatment. All the dogs recovered completely after five days of therapy. Earlier studies also reported that antibiotic treatment with ceftriaxonetazobactum had proven effective in clinical recovery against canine parvoviral gastroenteritis (Bhargavi et al., 2017). Ampicillin-cloxacillin was also found to be effective in clinical recovery from canine parvoviral gastroenteritis (Bishnoi et al., 2016). Several workers reported that NAC proved to be effective in treating affected cases of canine parvo virus gastroenteritis (Gaykwad et al., 2016). The antioxidant mechanism of vitamin $\mathrm{C}$ is based on the donation of hydrogen atom to lipid radicals, quenching of singlet oxygen, and removal of molecular oxygen (Levine et al., 1999). Similarly N-acetylcysteine (NAC), the body's primary cellular antioxidant, is a precursor to glutathione and its role on glutathione maintenance and metabolism is well established.

NAC along with vitamin $\mathrm{C}$ and vitamin $\mathrm{E}$ had been found to be effective in treating gastritis and peptic ulcers in dogs (Patel et al., 2018). In accordance with the earlier findings in the present study the inclusion of NAC and Vitamin $\mathrm{C}$ as an adjunct therapy with broad spectrum antibiotics had proved to be the most effective as compared to the administration of antibiotic alone in early recovery of gastroenteritic dogs on the basis of remission of clinical signs.

\section{Haematological findings}

Alterations in the mean values of haemoglobin and PCV in all the affected groups remained non-significantly lower and higher respectively as compared to the healthy group of dogs on day 0. A nonsignificant increase in the mean values of haemoglobin was observed on day 3 and day 5 of therapy in all the treatment groups (Table 2). Anaemia in the affected dogs might be due to the loss of blood during intestinal and gastric haemorrhages as also reported by Bhargavi et al., (2017).

Increased levels of PCV might be due to fluid loss through vomiting and diarrhoea causing dehydration as also observed by Bhargavi et al., (2017). On the other hand, Bhat et al., (2013) reported decreased mean levels of PCV due to intestinal bleeding. In contrast to the present findings, Weiss and Tvedten (2004) reported increase in the mean levels of haemoglobin which might be due to dehydration caused in gastroenteritic dogs.

The increase in haemoglobin levels after antibiotic therapy along with other supportive and symptomatic treatment was also reported by Bishnoi et al., (2016) and Agnihotri et al., (2017). Significantly higher $(P<0.05)$ mean levels of neutrophil were observed in the affected dogs in group 6 and 7 on day 0 before the start of treatment. Neutrophilia found in the present study might be associated with secondary bacterial complications. 
Table.2 Alterations in hematological parameters (Mean \pm S.E.) of CPV positive dogs $(n=21)$ in different therapeutic groups

\begin{tabular}{|c|c|c|c|c|c|c|c|c|}
\hline Parameters & Day & $\begin{array}{l}\text { Group } 1 \\
(n=6)\end{array}$ & $\begin{array}{l}\text { Group } 2 \\
(n=3)\end{array}$ & $\begin{array}{l}\text { Group } 3 \\
(n=3)\end{array}$ & $\begin{array}{c}\text { Group } 4 \\
(n=2)\end{array}$ & $\begin{array}{l}\text { Group } 5 \\
(n=3)\end{array}$ & $\begin{array}{l}\text { Group } 6 \\
(n=5)\end{array}$ & $\begin{array}{c}\text { Group } 7 \\
(n=5)\end{array}$ \\
\hline \multirow{3}{*}{$\begin{array}{l}\text { Hemoglobin } \\
\qquad(\mathrm{gm} / \mathrm{dl})\end{array}$} & 0 & $10.67 \pm 0.69$ & $10.13 \pm 1.62$ & $8.60 \pm 1.73$ & $10.65 \pm 0.85$ & $11.43 \pm 2.80$ & $10.64 \pm 1.66$ & $9.84 \pm 0.70$ \\
\hline & 3 & $10.67 \pm 0.69$ & $10.87 \pm 1.03$ & $9.03 \pm 0.96$ & $10.75 \pm 0.55$ & $11.97 \pm 2.53$ & $11.26 \pm 1.30$ & $10.42 \pm 0.60$ \\
\hline & 5 & $10.67 \pm 0.69$ & $10.93 \pm 0.95$ & $10.23 \pm 1.73$ & $11.20 \pm 0.90$ & $12.73 \pm 1.75$ & $12.20 \pm 0.91$ & $10.98 \pm 0.47$ \\
\hline \multirow{3}{*}{$\begin{array}{l}\mathrm{PCV} \\
(\%)\end{array}$} & 0 & $34.83 \pm 2.71$ & $39.70 \pm 2.65$ & $38.53 \pm 3.19$ & $35.50 \pm 4.50$ & $36.33 \pm 5.78$ & $40.26 \pm 2.15$ & $38.80 \pm 0.92$ \\
\hline & 3 & $34.83 \pm 2.71$ & $37.23 \pm 2.43$ & $36.10 \pm 5.16$ & $34.98 \pm 1.00$ & $35.00 \pm 7.21$ & $36.00 \pm 3.39$ & $36.00 \pm 2.77$ \\
\hline & 5 & $34.83 \pm 2.71$ & $35.60 \pm 4.54$ & $35.42 \pm 3.66$ & $34.00 \pm 3.00$ & $34.33 \pm 4.41$ & $35.96 \pm 4.23$ & $34.20 \pm 0.91$ \\
\hline \multirow{3}{*}{$\begin{array}{c}\text { TLC } \\
\left(\mathrm{m} / \mathrm{mm}^{3}\right)\end{array}$} & 0 & $13.02 \pm 0.54$ & $8.11 \pm 3.21$ & $23.40 \pm 7.34$ & $5.71 \pm 4.34$ & $10.06 \pm 0.39$ & $10.17 \pm 2.14$ & $18.15 \pm 8.04$ \\
\hline & 3 & $13.02 \pm 0.54$ & $10.17 \pm 0.58$ & $19.54 \pm 5.36$ & $7.45 \pm 3.95$ & $11.26 \pm 0.17$ & $11.24 \pm 0.69$ & $15.58 \pm 5.80$ \\
\hline & 5 & $13.02 \pm 0.54$ & $11.62 \pm 0.59$ & $14.67 \pm 4.68$ & $10.28 \pm 1.02$ & $12.96 \pm 0.85$ & $12.33 \pm 0.87$ & $14.80 \pm 3.58$ \\
\hline \multirow{3}{*}{$\begin{array}{l}\text { Neutrophil } \\
(\%)\end{array}$} & 0 & $72.17 \pm 2.95$ & $83.33 \pm 5.46$ & $82.00 \pm 9.85$ & $76.50 \pm 6.50$ & $82.00 \pm 2.08$ & $88.4 \pm 01.66^{b}$ & $86.40 \pm 2.54^{b}$ \\
\hline & 3 & $72.17 \pm 2.95$ & $79.00 \pm 5.51$ & $85.33 \pm 1.86$ & $75.00 \pm 3.00$ & $81.33 \pm 1.20$ & $82.60 \pm 2.20^{\mathrm{a}}$ & $82.80 \pm 2.18^{a b}$ \\
\hline & 5 & $72.17 \pm 2.95$ & $77.33 \pm 3.93$ & $82.67 \pm 1.86$ & $74.50 \pm 1.50$ & $76.67 \pm 1.20$ & $79.60 \pm 0.75^{\mathrm{a}}$ & $77.00 \pm 1.34^{\mathrm{a}}$ \\
\hline \multirow{3}{*}{$\begin{array}{l}\text { Lymphocyte } \\
(\%)\end{array}$} & 0 & $23.17 \pm 3.71$ & $14.33 \pm 5.70$ & $15.00 \pm 9.61$ & $22.00 \pm 6.00$ & $14.00 \pm 3.06$ & $8.80 \pm 0.58$ & $12.00 \pm 1.52$ \\
\hline & 3 & $23.17 \pm 3.71$ & $17.33 \pm 5.36$ & $8.67 \pm 1.86$ & $21.00 \pm 5.00$ & $11.67 \pm 0.88$ & $12.00 \pm 0.71$ & $14.00 \pm 1.82$ \\
\hline & 5 & $23.17 \pm 3.71$ & $21.33 \pm 3.18$ & $11.00 \pm 1.53$ & $22.50 \pm 2.50$ & $18.67 \pm 0.88$ & $17.00 \pm 1.10$ & $20.40 \pm 1.36$ \\
\hline \multirow{3}{*}{$\begin{array}{l}\text { Monocyte } \\
(\%)\end{array}$} & 0 & $3.50 \pm 0.62$ & $1.00 \pm 0.00$ & $2.67 \pm 1.20$ & $1.50 \pm 0.50$ & $2.50 \pm 0.50$ & $4.25 \pm 1.32$ & $2.00 \pm 0.00$ \\
\hline & 3 & $3.50 \pm 0.62$ & $1.33 \pm 0.33$ & $4.67 \pm 0.67$ & $3.50 \pm 1.50$ & $5.33 \pm 0.67$ & $1.25 \pm 1.70$ & $4.00 \pm 1.29$ \\
\hline & 5 & $3.50 \pm 0.62$ & $2.00 \pm 0.00$ & $5.33 \pm 0.88$ & $2.00 \pm 0.00$ & $3.67 \pm 0.88$ & $3.75 \pm 0.85$ & $3.25 \pm 1.11$ \\
\hline \multirow{3}{*}{$\begin{array}{l}\text { Eosinophil } \\
(\%)\end{array}$} & 0 & $2.33 \pm 0.33$ & $2.00 \pm 0.00$ & $0.00 \pm 0.00$ & $0.00 \pm 0.00$ & $3.50 \pm 1.50$ & $0.00 \pm 0.00$ & $0.00 \pm 0.00$ \\
\hline & 3 & $2.33 \pm 0.33$ & $2.33 \pm 0.67$ & $2.00 \pm 0.00$ & $0.00 \pm 0.00$ & $2.50 \pm 0.50$ & $0.00 \pm 0.00$ & $0.00 \pm 0.00$ \\
\hline & 5 & $2.33 \pm 0.33$ & $0.00 \pm 0.00$ & $2.00 \pm 0.00$ & $1.00 \pm 0.00$ & $1.33 \pm 0.05$ & $1.33 \pm 0.05$ & $0.00 \pm 0.00$ \\
\hline \multirow{3}{*}{$\begin{array}{l}\text { Thrombocytes } \\
\qquad\left(\mathrm{m} / \mathrm{mm}^{3}\right)\end{array}$} & 0 & $418.00 \pm 59.03$ & $289.17 \pm 49.07$ & $266.50 \pm 77.57$ & $246.83 \pm 25.31$ & $312.33 \pm 76.09$ & $285.17 \pm 64.35$ & $195.60 \pm 39.54$ \\
\hline & 3 & $418.00 \pm 59.03$ & $317.50 \pm 70.68$ & $344.00 \pm 75.70$ & $296.60 \pm 26.20$ & $344.75 \pm 80.78$ & $378.20 \pm 42.32$ & $312.67 \pm 25.22$ \\
\hline & 5 & $418.00 \pm 59.03$ & $351.5 \pm 38.10$ & $408.00 \pm 38.59$ & $340.20 \pm 12.24$ & $399.00 \pm 30.72$ & $413.67 \pm 77.11$ & $417.33 \pm 53.63$ \\
\hline
\end{tabular}

The means bearing different superscripts $(\mathrm{a}, \mathrm{b}$ and $\mathrm{c})$ differ significantly $(\mathrm{P}<0.05)$ within the groups. 
Table.3 Alterations in biochemical parameters and electrolytes (Mean \pm S.E.) in CPV positive dogs $(n=21)$ in different therapeutic groups

\begin{tabular}{|c|c|c|c|c|c|c|c|c|}
\hline Parameters & Day & $\begin{array}{l}\text { Group } 1 \\
(n=6)\end{array}$ & $\begin{array}{l}\text { Group } 2 \\
(n=3)\end{array}$ & $\begin{array}{l}\text { Group } 3 \\
(n=3)\end{array}$ & $\begin{array}{l}\text { Group } 4 \\
(n=2)\end{array}$ & $\begin{array}{l}\text { Group } 5 \\
(n=3)\end{array}$ & $\begin{array}{l}\text { Group } 6 \\
(n=5)\end{array}$ & $\begin{array}{l}\text { Group } 7 \\
(n=5)\end{array}$ \\
\hline \multirow{3}{*}{$\begin{array}{l}\text { ALT } \\
(\mathrm{IU} / \mathrm{L})\end{array}$} & 0 & $29.95 \pm 2.59$ & $37.83 \pm 3.67$ & $35.93 \pm 1.67$ & $38.35 \pm 4.45$ & $40.73 \pm 3.79$ & $39.32 \pm 6.01$ & $33.98 \pm 2.80$ \\
\hline & 3 & $29.95 \pm 2.59$ & $29.87 \pm 4.51$ & $29.20 \pm 0.61$ & $33.30 \pm 12.10$ & $32.27 \pm 6.37$ & $32.48 \pm 3.99$ & $29.92 \pm 4.23$ \\
\hline & 5 & $29.95 \pm 2.59$ & $28.76 \pm 2.44$ & $28.37 \pm 4.04$ & $28.80 \pm 8.00$ & $29.67 \pm 5.97$ & $29.16 \pm 3.61$ & $28.70 \pm 2.99$ \\
\hline \multirow{3}{*}{$\begin{array}{l}\text { AST } \\
(\mathrm{IU} / \mathrm{L})\end{array}$} & 0 & $39.27 \pm 3.74$ & $38.10 \pm 4.54$ & $38.10 \pm 4.54$ & $42.95 \pm 6.85$ & $50.27 \pm 12.90$ & $40.34 \pm 8.00$ & $45.94 \pm 9.67$ \\
\hline & 3 & $39.27 \pm 3.74$ & $37.27 \pm 3.40$ & $37.27 \pm 3.40$ & $40.70 \pm 11.30$ & $40.20 \pm 6.93$ & $39.80 \pm 2.00$ & $42.79 \pm 6.80$ \\
\hline & 5 & $39.27 \pm 3.74$ & $36.17 \pm 3.60$ & $36.17 \pm 3.60$ & $38.90 \pm 11.50$ & $38.87 \pm 2.67$ & $38.24 \pm 6.16$ & $38.14 \pm 1.48$ \\
\hline \multirow{3}{*}{$\begin{array}{l}\text { Total Protein } \\
\text { (g/dl) }\end{array}$} & 0 & $6.38 \pm 0.29$ & $6.69 \pm 0.33$ & $7.73 \pm 2.13$ & $7.50 \pm 0.08$ & $6.17 \pm 1.12$ & $6.91 \pm 1.32$ & $7.10 \pm 1.27$ \\
\hline & 3 & $6.38 \pm 0.29$ & $6.45 \pm 0.31$ & $6.67 \pm 0.22$ & $6.50 \pm 1.20$ & $5.86 \pm 1.16$ & $6.78 \pm 1.26$ & $6.58 \pm 1.17$ \\
\hline & 5 & $6.38 \pm 0.29$ & $5.94 \pm 0.58$ & $6.50 \pm 1.20$ & $6.34 \pm 1.23$ & $5.53 \pm 1.13$ & $6.22 \pm 0.89$ & $6.25 \pm 1.06$ \\
\hline \multirow{3}{*}{$\begin{array}{l}\text { BUN } \\
(\mathrm{mg} / \mathrm{dl})\end{array}$} & 0 & $20.72 \pm 2.17$ & $41.03 \pm 11.82$ & $62.00 \pm 30.85$ & $68.60 \pm 34.60$ & $64.40 \pm 20.24$ & $74.60 \pm 33.14$ & $70.36 \pm 40.80$ \\
\hline & 3 & $20.72 \pm 2.17$ & $38.63 \pm 8.20$ & $58.37 \pm 30.90$ & $59.60 \pm 27.40$ & $46.17 \pm 15.97$ & $61.30 \pm 30.22$ & $46.042 \pm 0.06$ \\
\hline & 5 & $20.72 \pm 2.17$ & $34.17 \pm 8.57$ & $49.23 \pm 20.87$ & $39.00 \pm 13.00$ & $41.33 \pm 8.51$ & $38.90 \pm 23.62$ & $35.76 \pm 9.79$ \\
\hline \multirow{3}{*}{$\begin{array}{l}\text { S. Creatinine } \\
(\mathrm{mg} / \mathrm{dl})\end{array}$} & 0 & $0.82 \pm 0.09$ & $0.93 \pm 0.20$ & $1.24 \pm 0.15$ & $0.93 \pm 0.17$ & $1.09 \pm 0.10 \mathrm{~b}$ & $1.46 \pm 0.64$ & $1.11 \pm 0.36$ \\
\hline & 3 & $0.82 \pm 0.09$ & $0.87 \pm 0.27$ & $1.22 \pm 0.14$ & $0.87 \pm 0.05$ & $0.87 \pm 0.04 \mathrm{a}$ & $1.30 \pm 0.43$ & $1.09 \pm 0.37$ \\
\hline & 5 & $0.82 \pm 0.09$ & $0.82 \pm 0.13$ & $1.07 \pm 0.19$ & $0.80 \pm 0.08$ & $0.81 \pm 0.04 \mathrm{a}$ & $1.08 \pm 0.19$ & $0.97 \pm 0.21$ \\
\hline \multirow{3}{*}{$\begin{array}{l}\text { Sodium } \\
(\mathrm{mEq} / \mathrm{L})\end{array}$} & 0 & $143.15 \pm 2.10$ & $132.70 \pm 9.91$ & $137.00 \pm 5.13$ & $132.45 \pm 6.35$ & $135.50 \pm 4.74$ & $136.52 \pm 3.68$ & $138.14 \pm 2.83$ \\
\hline & 3 & $143.15 \pm 2.10$ & $134.93 \pm 17.56$ & $139.40 \pm 3.25$ & $136.60 \pm 8.60$ & $137.93 \pm 3.54$ & $137.32 \pm 3.13$ & $139.00 \pm 2.04$ \\
\hline & 5 & $143.15 \pm 2.10$ & $137.43 \pm 13.54$ & $141.93 \pm 1.94$ & $142.05 \pm 8.05$ & $139.20 \pm 3.31$ & $138.12 \pm 4.29$ & $140.68 \pm .67$ \\
\hline \multirow{3}{*}{$\begin{array}{l}\text { Potassium } \\
(\mathrm{mEq} / \mathrm{L})\end{array}$} & 0 & $5.20 \pm 0.22$ & $3.78 \pm 0.27$ & $4.29 \pm 0.28$ & $4.25 \pm 0.38$ & $4.56 \pm 0.04$ & $4.26 \pm 0.80$ & $4.31 \pm 0.28$ \\
\hline & 3 & $5.20 \pm 0.22$ & $4.27 \pm 0.54$ & $4.33 \pm 0.40$ & $4.37 \pm 0.02$ & $4.82 \pm 0.20$ & $4.98 \pm 0.57$ & $4.89 \pm 0.13$ \\
\hline & 5 & $5.20 \pm 0.22$ & $4.45 \pm 0.90$ & $4.56 \pm 0.57$ & $4.65 \pm 0.92$ & $5.18 \pm 0.42$ & $5.22 \pm 0.51$ & $5.14 \pm 0.22$ \\
\hline \multirow{3}{*}{$\begin{array}{l}\text { Chloride } \\
(\mathrm{mEq} / \mathrm{L})\end{array}$} & 0 & $107.80 \pm 1.05$ & $101.30 \pm 8.76$ & $101.03 \pm 7.48$ & $103.75 \pm 6.75$ & $101.90 \pm 2.99$ & $103.00 \pm 4.08$ & $105.36 \pm 3.28$ \\
\hline & 3 & $107.80 \pm 1.05$ & $102.57 \pm 16.34$ & $103.20 \pm 6.40$ & $104.60 \pm 2.90$ & $104.10 \pm 4.32$ & $107.38 \pm 2.85$ & $106.00 \pm 3.23$ \\
\hline & 5 & $107.80 \pm 1.05$ & $103.23 \pm 16.14$ & $105.57 \pm 1.02$ & $106.15 \pm 3.05$ & $105.27 \pm 1.63$ & $108.64 \pm 2.87$ & $108.71 \pm 1.73$ \\
\hline
\end{tabular}


On day 3 and day 5 of therapy, a significant decrease in neutrophil count $(\mathrm{P}<0.05)$ was observed within the CPV positive dogs in group 6 and 7. Significant decrease in total leucocyte count and neutrophil count was also reported by Agnihotri et al., (2017) and Bishnoi et al., (2016) in their studies after 7 days of treatment with antibiotics.

A non-significant lower $(\mathrm{P}<0.05)$ mean platelet count was observed in CPV positive dogs of all the treatment groups than control group at the start of therapy on day 0 . Thrombocytopenia observed in the present study could be due to decreased platelet production or as a result of direct action of viruses and immunologic components on platelets or endothelium as suggested in a study by Shah et al., (2013). A nonsignificant increase was observed in platelet count in CPV positive dogs on day 3 and day 5 of therapy. Significant findings related to the increased platelet count were reported by Agnihotri et al., (2017) and Bishnoi et al., (2016) earlier in the similar studies.

\section{Biochemical findings}

No significant alterations with respect to biochemical parameters was observed in the CPV positive dogs in the treatment groups as compared to the control group at the start of therapy (Table 3). Though the elevated levels of ALT before treatment could be due to reactive hepatopathy as also suggested by Berghoff and Steiner (2011). Following therapy a non-significant decrease was observed in ALT and AST values in CPV positive dogs. CPV positive dogs showed decreased values of total protein than healthy control at the start of therapy which might be due to anorexia and decreased absorption through villi of intestines as also observed by Sagar et al., (2008).

The non-significant $(\mathrm{P}<0.05)$ decrease in mean total proteins level in CPV positive dogs was observed at day 3 and 5 of treatment. Non-significant decrease in the mean values of total protein was also observed on day 7 of treatment by Bishnoi et al., (2016). BUN values were significantly higher $(\mathrm{P}<0.05)$ in the $\mathrm{CPV}$ positive dogs than the control group at the start of therapy. The increased values of BUN are suggestive of pre renal azotemia because of reduced glomerular filtration rate.

Non-significant higher mean levels of serum creatinine were observed in CPV positive dogs than control group at day 0 of therapy. Non-significant decrease was observed in BUN and creatinine values in CPV positive dogs on day 3 and 5 of treatment.

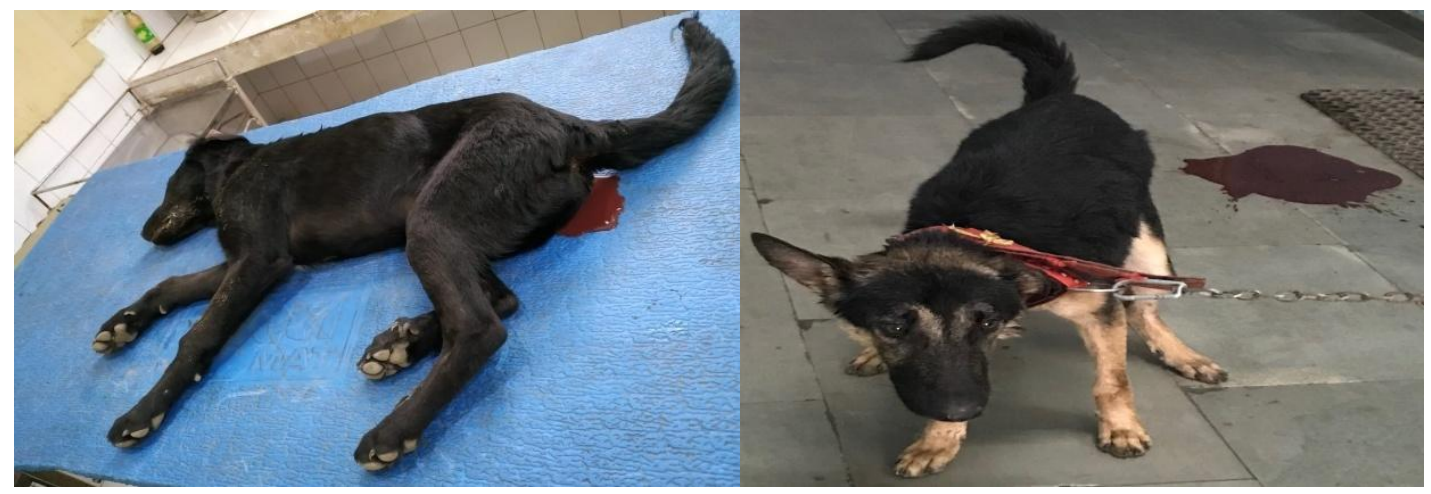

Figure.2 \& 3 CPV infected dogs showing haemorrhagic diarrhoea, dehydration and depression. 
All the electrolyte parameters showed nonsignificant lower values in CPV positive group than healthy control group at the start of therapy due to losses through vomition and diarrhoea as also observed in similar studies by Panda et al., (2009). Non-significant increase in electrolyte parameters was observed on day 3 and 5 of therapy.

CPV positive dogs showed anaemia with increased packed cell volume, leucocytosis, neutrophilia with thrombocytopenia along with elevated liver and kidney function parameters and decreased serum electrolytes. Adjunct antibiotic therapy with Vitamin C and $\mathrm{N}$-acetylcysteine have an additive effect in assisting early recovery with restoration of haemato-biochemical parameters when compared with the groups which were administered with antibiotics alone.

\section{References}

Agnihotri, D., Singh, Y., Maan, S., Jain, V. and Kumar, A. (2017). Molecular detection and clinic-haematological study of viral gastroenteritis in dogs. Har. Vet. 56(1): 72-76.

Akgul, G., Bicici, O., Sahın, T., Baldaz, V., Celik, O.Y. and Erdeger, A. (2019). Clinical Pictures and Some Risk Factors Associated with Canine Parvoviral Enteritis in Dogs at Siirt City of Turkey. Alexandria J. Vet. Sci.60(1): $10-14$

Bishnoi, S. (2016). Studies on diagnosis and therapeutic management of canine parvovirus (CPV) infection. M.V.Sc. Thesis, Lala Lajpat Rai Univeristy of Veterinary and Animal Sciences, Hisar.

Berghoff, N. and Steiner, J. M. (2011). Laboratory tests for the diagnosis and management of chronic canine and feline enteropathies. Vet. Clin. Small Anim. 41: 311-328.

Bhargavi, M., Shobhamani, B., Kumari, K. N. and Srilatha, C. (2017). Diagnostic Aspects and Haematobiochemical Changes Associated with Canine Parvoviral Enteritis in Dogs. Int. J. Curr. Microbiol. App. Sci. 6(11): 33573364.

Bhat, A. A., Wadhwa, D. R., and Khan, M. A. (2013). Therapeutic management of canine parvo viral (CPV) gastroenteritis. Vet. Practitioner, 14(1): 96-97.

Cavalli, A., Martella, V., Costantina, D., Michele, C., Anna, L.B., Pasquale, D.P., Nicola, D., Gabriella, E. and Buonavoglia, C. (2008). Evaluation of the antigenic relationships among canine parvovirus type 2 variants. Clin. Vaccine Immunol. 15(3): 534-539.

Decaro, N., Desario, C., Campolo, M., Cavalli, A. and Ricci, D. (2004). Evaluation of the lactogenic immunity to canine parvovirus in pups. New Microbiol. 27(4): 375-379.

Decaro, N.,Desario, C., Addie, D. D., Martella, V., Vieira, M. J., Elia, G., Zicola, A., Davis, C., Thompson, G., Thiry, E., Truyen, U. and Buonavoglia, C. (2007). The study molecular epidemiology of canine parvovirus, Europe. Emerg. Infect. Dis. 13: 12221224.

Gaykwad, C., Garkhal, J., Chethan, G. E., Nandi, S. and De, U. K. (2016). Amelioration of oxidative stress using $\mathrm{N}$ - acetylcysteine in canine parvoviral enteritis. J. Vet. Pharma. Thera. 41(1): 68-75.

Hao, X., Liu, R., He, Y., Xiao, X., Xiao, W. and Zheng, Q. (2019). Multiplex PCR methods for detection of several viruses associated with canine respiratory and enteric diseases. PLoS ONE, 14(3): $\mathrm{e} 0213295$

Kaur, G., Chandra, M., Dwivedi, P. N. and Narang, D. (2016). Multiplex real-time PCR for identification of canine 
parvovirus antigenic types.J. Virol. Methods, 233: 1-5.

Kumar, M., Chidri, S. and Nandi, S. (2011). A sensitive method to detect canine parvoviral DNA in faecal samples by nested polymerase chain reaction. Ind. J. Biotec. 10:183-187.

Levine, M., Rumsey, S. C., Daruwala, R., Park, J. B. and Wang, Y. (1999). Criteria and recommendations for vitamin $\mathrm{C}$ intake.J. Ame. Med. Ass. 281(15): 1415-1423.

Panda, D., Patra, R. C., Nandi, S. and Swarup, D. (2009). Oxidative stress indices in gastroenteritis in dogs with canine parvoviral infection. Res. Vet. Sci. 86: $36-42$.

Patel, P. K., Patel, S. K., Dixit, S. K. and Rathore, R. S. (2018). Gastritis and Peptic Ulcer Diseases in Dogs: A Review. Int. J. Curr. Microbiol. App. Sci. 7(3): 2475-2501.

Shah, S. A., Sood, N. K., Wani, N., Gupta, K. and Singh, A. (2013). Haemato- biochemical changes in canine parvoviral infection. Ind. J. Vet. Pathol. 37(2): 131-133.

Sagar, A., Roy, S. and Roy, M. (2008). Clinico, haemato-biochemical changes and diagnosis of canine parvoviral enteritis. Intas Polivet, 9(2): 262-265.

Srinivas, V. M. V., Mukhopadhyay, H. K., Antony, P. X. and Pillai, R. M. (2013). Molecular epidemiology of canine parvovirus in Southern India. Vet. World, 6(10): 744-749.

Surendhar, M., Bharathi, M. V., Selvaraju, G., Rathnapraba, S. and Kumar, R. R. (2018). Molecular epidemiology and evaluation of haemato-biochemical parameters in canine parvoviral enteritis dogs in Chennai, India. Ind. J. Chem. Studies, 6(6):119-123.

Weiss, D. and Tvedten, H. (2004). Erythrocyte disorders. Small Animal Clinical Diagnosis by Laboratory Methods (fourth edition), W.B. Saunders, Philadelphia: 38-62.

\section{How to cite this article:}

Kataria. D., D. Agnihotri, V. K. Jain, G. Charaya and Singh. Y. 2020. Molecular Occurrence and Therapeutic Management of Canine Parvovirus Infection in Dogs. Int.J.Curr.Microbiol.App.Sci. 9(02): 1770-1779. doi: https://doi.org/10.20546/ijcmas.2020.902.202 